\title{
Environmental Drivers of Ranavirus in Free-Living Amphibians in Constructed Ponds
}

\author{
Tess E. Youker-Smith $\left(\mathbb{0},{ }^{1}\right.$ Philipp H. Boersch-Supan $\left(\mathbb{D},{ }^{2,3}\right.$ Christopher M. Whipps $\left(\mathbb{D},{ }^{1}\right.$ \\ and Sadie J. Ryan $\mathbb{1}^{2,3}$ \\ ${ }^{1}$ Department of Environmental and Forest Biology, State University of New York College of Environmental Science and Forestry, Syracuse, NY 13210 \\ ${ }^{2}$ Quantitative Disease Ecology and Conservation (QDEC) Lab, Department of Geography, University of Florida, 3128 Turlington Hall, Gainesville, FL \\ 32601 \\ ${ }^{3}$ Emerging Pathogens Institute, University of Florida, Gainesville, FL 32610
}

\begin{abstract}
Amphibian ranaviruses occur globally, but we are only beginning to understand mechanisms for emergence. Ranaviruses are aquatic pathogens which can cause $>90 \%$ mortality in larvae of many aquaticbreeding amphibians, making them important focal host taxa. Host susceptibilities and virulence of ranaviruses have been studied extensively in controlled laboratory settings, but research is needed to identify drivers of infection in natural environments. Constructed ponds, essential components of wetland restoration, have been associated with higher ranavirus prevalence than natural ponds, posing a conundrum for conservation efforts, and emphasizing the need to understand potential drivers. In this study, we analyzed 4 years of Frog virus 3 prevalence and associated environmental parameters in populations of wood frogs (Lithobates sylvaticus) and green frogs (Lithobates clamitans) in a constructed pond system. High prevalence was best predicted by low temperature, high host density, low zooplankton concentrations, and Gosner stages approaching metamorphosis. This study identified important variables to measure in assessments of ranaviral infection risk in newly constructed ponds, including effects of zooplankton, which have not been previously quantified in natural settings. Examining factors mediating diseases in natural environments, particularly in managed conservation settings, is important to both validate laboratory findings in situ, and to inform future conservation planning, particularly in the context of adaptive management.
\end{abstract}

Keywords: Ranavirus, Frog virus 3, Constructed wetlands, Lithobates sylvaticus, Lithobates clamitans, Vernal pools

\section{INTRODUCTION}

Electronic supplementary material: The online version of this article (https://doi. org/10.1007/s10393-018-1350-5) contains supplementary material, which is available to authorized users.

Published online: August 9, 2018

Correspondence to: Sadie J. Ryan, e-mail: sjryan@ufl.edu
Ranaviruses are primarily infectious pathogens of aquatic ectothermic vertebrates and have been implicated in mass die-offs of amphibians worldwide (Duffus et al. 2015). Many anuran species, including the wood frog (Lithobates sylvaticus), experience nearly $100 \%$ mortality after exposure as larvae (Hoverman et al. 2011). Little is currently known 
about reasons for ranavirus emergence, although anthropogenic disturbance is suspected as a leading factor (Jancovich et al. 2005; Forson and Storfer 2006; Storfer et al. 2007; Miller et al. 2009). With increasing awareness of potential human influence, research efforts are aimed at identifying risk factors for infection with the goal of reducing both spread and persistence of ranaviruses. In this study, we identified factors influencing prevalence of Frog virus 3 (FV3), a widespread ranavirus, in populations of $L$. sylvaticus and green frogs (Lithobates clamitans) in a constructed vernal pool array in New York State, USA, by developing statistical models of prevalence in response to environmental and organism-focused variables.

Individual factors have been evaluated in controlled settings to determine virulence of ranaviruses both in the environment and within hosts. Ranaviral replication rates in vitro generally increase as temperature increases (Ariel et al. 2009); however, ranaviral infectivity declines at a faster rate at higher temperatures (Nazir et al. 2012; Munro et al. 2016). Ranaviruses may persist in the environment for several weeks to months in dry conditions (Nazir et al. 2012; Munro et al. 2016). This raises concern when examining recurring outbreaks because many wetland types that support populations of aquatic-breeding anurans in the northeastern USA may partially or completely dry up during late summer or over winter. Furthermore, the interplay of pond-drying and other abiotic factors on the prevalence and infection dynamics of aquatic diseases remains poorly understood (Paull and Johnson 2018). Vernal pools also support highly diverse microbial and microinvertebrate communities, and although less rigorously studied, these communities could be highly influential in understanding outbreak etiology. For example, FV3 becomes less virulent in the presence of zooplankton (Johnson and Brunner 2014) and survives longer in filtered and sterilized water (Nazir et al. 2012; Johnson and Brunner 2014; Munro et al. 2016).

In addition to environmental conditions, we examined several variables shown to affect susceptibility of amphibians to FV3 including developmental stage, and density. Although both L. sylvaticus and L. clamitans have relatively high probabilities of infection and mortality when exposed to FV3, we expect highest prevalence rates overall in $L$. sylvaticus (Hoverman et al. 2011). Water temperature produces different results with respect to infectivity and mortality, depending on both Ranavirus strain and host species (Rojas et al. 2005; Bayley et al. 2013; Echaubard et al. 2014; Brand et al. 2016). In regards to specifically FV3 and anuran ranid species (which includes L. sylvaticus and L. clamitans), research has produced conflicting results. Many controlled studies supported a positive correlation, with higher mortality rates at warmer temperatures (Bayley et al. 2013; Brand et al. 2016). In contrast, Echaubard et al. (2014) and Gray et al. (2007) found that probability of both infection and mortality was lower at warmer temperatures. In a natural setting, seasonal increases in temperature generally correspond with progression toward metamorphosis in aquatic anuran larvae, measured by increases in Gosner developmental stage (Gosner 1960). When examining Gosner stage alone, different species exhibit differing trends in susceptibility, but in ranid species infection and mortality generally increase as larvae approach metamorphosis (Haislip et al. 2011; Warne et al. 2011). It is unclear what role host density may play in FV3 outbreaks, as response to density is nonlinear; other factors such as behavior, metamorphic rates, and baseline host fitness differ in low versus high density conditions and blur the effects of ranaviruses (Greer et al. 2008; Echaubard et al. 2010; Reeve et al. 2013).

Over a 4-year study period, we recorded estimated FV3 prevalence and developed explanatory models of prevalence in response to temperature, larval density, Gosner stage, spatial clustering of pools, and zooplankton communities. The objectives of this study were to better understand the influence of environmental and host conditions on FV3 outbreaks in natural settings; furthermore we specifically wanted to quantify the effect of zooplankton on FV3 prevalence within natural systems. The use of newly constructed ponds in the study site presented a unique opportunity to assess FV3 risk in ponds that have a known history and were monitored since their creation.

\section{Methods}

\section{Study Site}

Svend O. Heiberg Memorial Forest $\left(42^{\circ} 46^{\prime} \mathrm{N}, 76^{\circ} 5^{\prime} \mathrm{W}\right)$ is a 1600 ha property owned and maintained by the State University of New York College of Environmental Science and Forestry (SUNY ESF). An array of 71 vernal pool basins (Fig. 1a) was constructed in 2010 by SUNY ESF and the Upper Susquehanna Coalition, to recreate L. sylvaticus and spotted salamander (Ambystoma maculatum) breeding habitat previously destroyed by land use change associated with the sequence of forest clearance, intensive agriculture, 

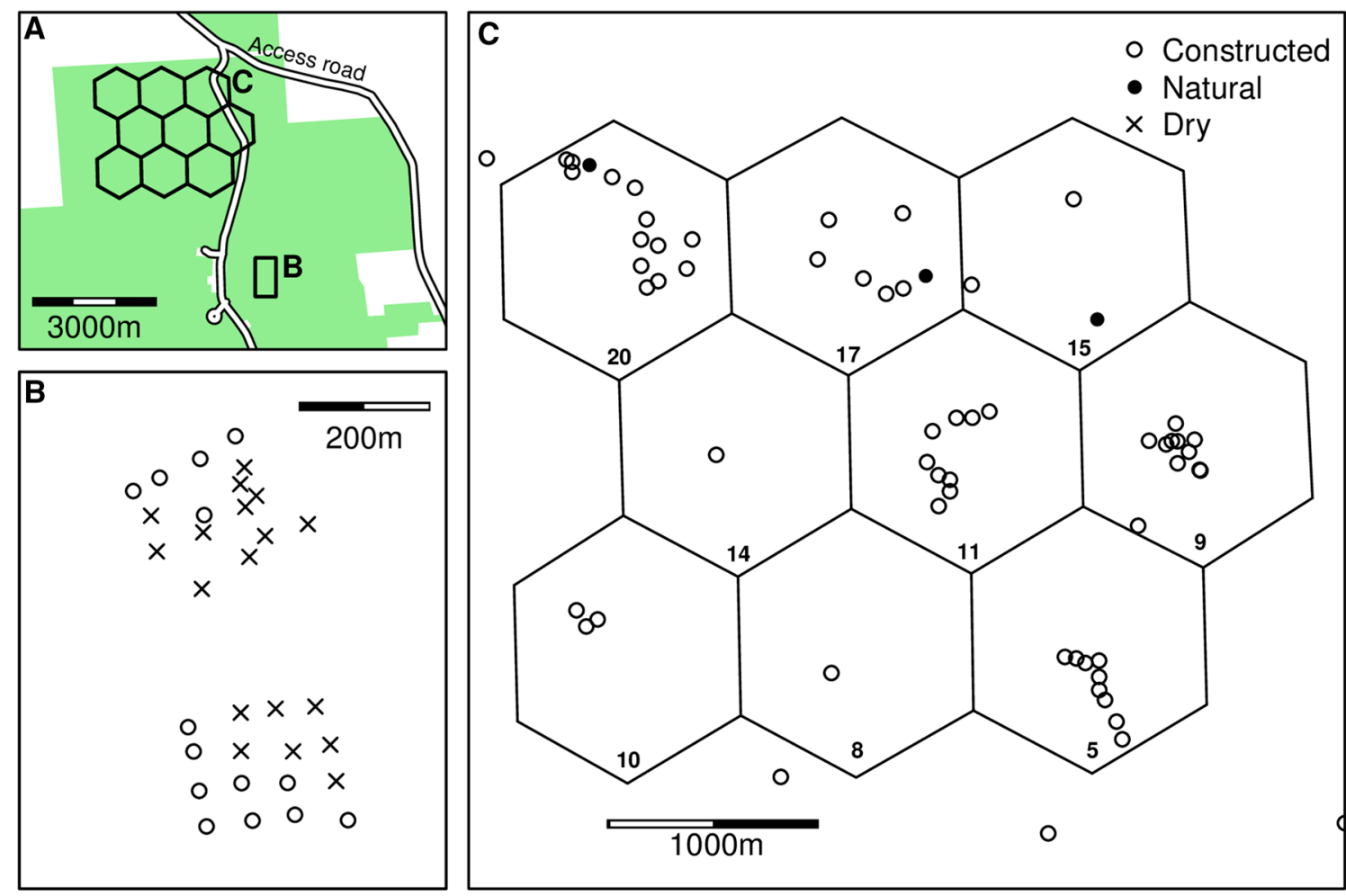

Fig. 1. a Vernal pool array within Heiberg Memorial Forest (shaded area). Pools were constructed (b) in a separate grid-patterned microarray, as well as (c) in clusters of 1, 3, or 9 pools within uniform landscape hexagonal areas. Study pools included constructed pools (open circles) with three pre-existing pools (filled circles). Sixteen pools failed to hold water at any point in the study, here designated as "dry" (crosses).

and subsequent agricultural abandonment and forest regrowth over the last two centuries. Pools varied from 3 to $10 \mathrm{~m}$ diameter, with most circular or ovular in shape. Pools were designed to be hydrologically isolated and were arranged in clusters of 1,3 , or 9 pools within 164-m-diameter landscape hexagons (Fig. 1c). A separate cluster of 32 pools, the "microarray" (Fig. 1b), was constructed in a grid pattern spanning forested, field, and edge habitats. Several naturally occurring vernal pools were also present within hexagon clusters.

\section{Sampling}

All constructed ponds containing water and four natural ponds were sampled at three separate intervals during $L$. sylvaticus larval development from 2011 to 2014. Sampling events were spaced 3 to 4 weeks apart and began approximately 6 to 8 weeks after L. sylvaticus egg masses were observed, allowing tadpoles to develop to at least Gosner stage 25 (Gosner 1960). First sampling intervals occurred from mid-May to early June, depending on timing of spring thaw and $L$. sylvaticus breeding events. Sampling in 2013 was restricted to one interval in June-July.
Larval sampling at each interval was performed by modified pipe sampling methods as described in Werner et al. (2007). A 33-cm-diameter section of spiral duct pipe was plunged through the water column into the sediment, and tadpoles trapped within the pipe were collected by net sweeps and stored in buckets with water from the same pool. A sample was considered empty once zero individuals were captured for ten consecutive net sweeps. Samples were spaced at least $2 \mathrm{~m}$ apart with the exception of pools less than $5 \mathrm{~m}$, from which approximately one sample per $2 \mathrm{~m}^{2}$ of surface area was taken. Equipment was immersed in 10\% bleach solution for at least $60 \mathrm{~s}$ and allowed to air dry between pools. Thirty tadpoles were randomly selected for processing in pools where at least 30 were captured, and all tadpoles were used in pools where fewer than 30 were captured. All other individuals were immediately returned to their pool of origin. Selected individuals were humanely euthanized by immersion in $70 \%$ ethanol, and stored in $95 \%$ ethanol at $4^{\circ} \mathrm{C}$ until further processing. Sampling was performed according to State University of New York College of Environmental Science and Forestry IACUC protocol \#140201. 


\section{Environmental and Organism-Focused Parameters}

Marked wooden stakes were driven into the sediment in the estimated deepest area of each pool, and visited weekly to record water depth from the first spring thaw until November. Two temperature loggers (Thermochron ${ }^{\circledR}$ iButtons ${ }^{\circledR}$, Embedded Data Systems, Lawrenceburg, KY) per pool were attached to $15 \mathrm{~cm}$ lengths of copper wire and coated with Performix ${ }^{\circledR}$ Plasti Dip ${ }^{\circledR}$ (Plasti Dip International, Blaine, MN). A length of epoxy coated rebar greater than the maximum depth for each pool was driven into the sediment near depth stakes, and one thermal logger was attached at the bottom of each pool. One thermal logger was affixed to the bottom of a foam float attached loosely to freely move up and down posts, to measure surface temperature. Thermal loggers were programmed to record readings every $3 \mathrm{~h}$ and were retrieved and redeployed every 6 months during the study period. Zooplankton concentrations were taken from Holmes et al. (2016). Briefly, zooplankton was sampled by passing $3 \mathrm{~L}$ of water, taken from the center of each pond, through an $80-\mu \mathrm{m}$ sieve. Animals were preserved in 95\% ethanol and manually counted and identified to the species level, or lowest taxonomic group possible when species could not be identified (Holmes et al. 2016).

\section{Ranaviral DNA Screening Methods}

PCR Assays

Screening for the presence of ranaviral DNA followed the methods outlined in Youker-Smith et al. (2016), and a full description of the employed protocols is given in the supplementary materials. Briefly, DNA was isolated and purified from up to $25 \mathrm{mg}$ tadpole liver tissue using a modified salt extraction method (Sambrook and Russell 2001). Template DNA $(5 \mu \mathrm{L})$ was then amplified with conventional PCR using primers for Frog virus 3 major capsid protein (MCP) 4 and 5 as described in Mao et al. (1997; MCP 4: 5'-GAC TTG GCC ACT TAT GAC-3'; MCP 5: 5'-GTC TCT GGA GAA GAA GAA-3'). Amplified base pair segments were separated by $1 \%$ agarose gel electrophoresis and stained with ethidium bromide for visualization. Sequenced DNA from a dead L. sylvaticus tadpole sampled in June 2011 from Hexagon 11 was used as positive control. Negative and ambiguous results were re-amplified using the above methods to increase screening sensitivity. For the 2014 samples negative or ambiguous results were re-analyzed via quantitative PCR using a protocol modified from Pallister et al. (2007).

\section{Sequencing}

Amplified PCR products from four dead or moribund $L$. sylvaticus collected from die-offs in Hexagons 11 and 5 (Fig. 1c) in 2011 were purified using Omega E.Z.N.A. ${ }^{\circledR}$ Cycle Pure Kit (Omega Bio-tek Inc., Norcross, GA). Purified products were sequenced at the Yale University DNA Analysis Facility. Sequences were aligned with BioEdit v 7.2.5 and a GenBank (Clark et al. 2016) sequence search performed using nucleotide BLAST ${ }^{\circledR}$, targeting nucleotide collection entries optimized for highly similar sequences (Johnson et al. 2008).

\section{Data Analysis}

Frog virus 3 (FV3) prevalence was modeled using hierarchical generalized linear regression models (GLMs) with binomial error distribution and logit link function in response to the following variables: temperature, water depth, Gosner developmental stage, tadpole host density, water depth, the average distance to the three nearest neighboring pools (as a measure of spatial clustering of pools), and total pelagic zooplankton concentration (Table 1, Figure S1). No temperature or zooplankton data were available for the single sampling interval in 2013, and the corresponding prevalence data were therefore excluded from the statistical analysis.

GLM parameters were estimated in a hierarchical Bayesian framework using the rstan (Carpenter et al. 2017) and rethinking (McElreath 2016) packages in R. This inference framework provided a coherent approach to modeling missing predictor values, which was essential to maintain a dataset representative of the sampling design, given that zooplankton data were only available for approximately $50 \%$ of samples (Table 1 ). Apart from the interpond distances, all other predictor variables exhibited a lesser degree of missingness (Temperature 9\%, Host density $16 \%$, Water level $20 \%$, Gosner stage $10 \%$ ) as a result of logistical constraints on sampling and/or equipment failures.

A hierarchical model structure was chosen to accommodate random intercepts for each of the nine sampling occasions. Model structure was as follows:

$$
N_{i j}^{\text {pos }} \sim \operatorname{Binomial}\left(N_{i j}^{\text {total }}, p_{i j}\right),
$$


Table 1. List of Explanatory Variables for Generalized Linear Models of Frog Virus 3 (FV3) Prevalence in Vernal Ponds.

\begin{tabular}{|c|c|c|c|c|}
\hline & Variable & Unit & Transformation & Missingness \\
\hline TEMP & Temperature & ${ }^{\circ} \mathrm{C}$ & N/A & $15 / 170$ \\
\hline DENS & Areal density & individuals $/ \mathrm{m}^{2}$ & Logarithmic & $27 / 170$ \\
\hline WLEV & Water depth & $\mathrm{cm}$ & N/A & $35 / 170$ \\
\hline GOSNER & Gosner developmental stage & Stage 1-46 (Gosner 1960) & N/A & $18 / 170$ \\
\hline DIST & Spatial clustering of pools & $\begin{array}{l}\text { Average straight line distance (in meters) to the nearest } 3 \\
\text { pools }\end{array}$ & Logarithmic & $0 / 170$ \\
\hline PLANK & $\begin{array}{l}\text { Pelagic zooplankton concen- } \\
\text { tration }\end{array}$ & individuals/L & Logarithmic & $82 / 170$ \\
\hline
\end{tabular}

Missingness gives the proportion of FV3 prevalence observations for which no corresponding observation of a particular environmental covariate was available.

where $N_{i j}^{p o s}$ are the number of FV3 positive tadpoles out of a sample of $N_{i j}^{\text {total }}$ in pool $i$ at sampling occasion $j$, and $p_{i j}$ is the expected FV3 prevalence, modeled itself as

$$
\operatorname{logit}\left(p_{i j}\right)=\beta_{0}+\beta_{1} X_{1 i}+\beta_{2} X_{2 i}+\ldots+\beta_{n} X_{n i}+W_{j},
$$

where $\beta_{1 \ldots n}$ are the regression coefficients for predictors $X_{1 \ldots n}$ for pool $i . W_{j}$ is the random intercept for sampling interval $j$, and was modeled as $W_{j} \sim \operatorname{Normal}\left(0, s_{W}\right)$. Further, missing predictor values $X_{n i}$ were estimated as coming from a normal distribution $X_{n i} \sim \operatorname{Normal}\left(m_{X_{n}}, s_{X_{n}}\right)$, the mean and variance of which were estimated from the observed values of each predictor jointly with all other model parameters.

Following recommendations in Gelman et al. (2008) and McElreath (2016) we employed weakly informative priors to regularize extreme inferences that can be obtained using maximum likelihood or completely non-informative priors. Normal $(0,10)$ priors were chosen for all regression coefficients, Half-Cauchy $(0,2)$ priors for all variance parameters. The priors for the mean $\mu_{X n}$ of a missing predictor values followed a normal distribution centered on the mean of the observed predictor values with a standard deviation of 10 .

Candidate models with different predictor combinations were evaluated using leave-one-out cross-validation (LOO) as implemented in the loo package in R (Vehtari et al. 2017) and ranked using the LOO information criterion $\mathrm{IC}_{\mathrm{LOO}} \cdot \mathrm{IC}_{\mathrm{LOO}}$ is asymptotically equal to the WatanabeAkaike information criterion (WAIC; Watanabe 2010) as a means for estimating pointwise out-of-sample prediction accuracy, but is more robust for finite sample sizes (Vehtari et al. 2017).

\section{Results}

DNA sequences obtained from four L. sylvaticus individuals exhibiting ranavirus pathologies in 2011 shared 100\% identity with Frog virus 3 isolate D1 major capsid protein gene (GenBank accession JQ771299).

\section{Frog Virus 3 Site-Wide Prevalence Ranged From 0.03 to 0.57}

The model with the highest predictive accuracy included temperature, Gosner stage, water level, host density, zooplankton density and a measure of spatial clustering as predictors (Table 2). Within this model, FV3 prevalence decreased with water temperature $(\beta=-0.25,95 \%$ CI $(-0.40,-0.11)$; Fig. 2a). and increased with increasing water level ( $\beta=0.05,95 \% \mathrm{CI}(0.03,0.17)$; Fig. $2 \mathrm{c})$. Further, prevalence increased with an increase in host density ( $\beta=0.32$, 95\% CI $(0.08,0.58)$; Fig. $2 \mathrm{~d})$, but decreased

Table 2. Posterior Estimates of Regression Coefficients for the Best Predictive Model.

\begin{tabular}{lrrcr}
\hline & \multicolumn{1}{c}{ Mean } & \multicolumn{2}{c}{ SD } & \multicolumn{2}{c}{$95 \%$ credible interval } \\
\hline Intercept & 3.22 & 2.37 & -1.30 & 7.60 \\
GOSNER & 0.08 & 0.05 & -0.01 & 0.17 \\
TEMP & -0.25 & 0.07 & -0.40 & -0.11 \\
$\log ($ DENS $)$ & 0.32 & 0.13 & 0.08 & 0.58 \\
WLEV & 0.05 & 0.01 & 0.03 & 0.07 \\
$\log ($ PLANK $)$ & -0.63 & 0.06 & -0.75 & -0.51 \\
$\log ($ DIST $)$ & -0.70 & 0.17 & -1.04 & -0.37 \\
$s_{W}$ & 1.54 & 0.49 & 0.84 & 2.63 \\
\hline
\end{tabular}



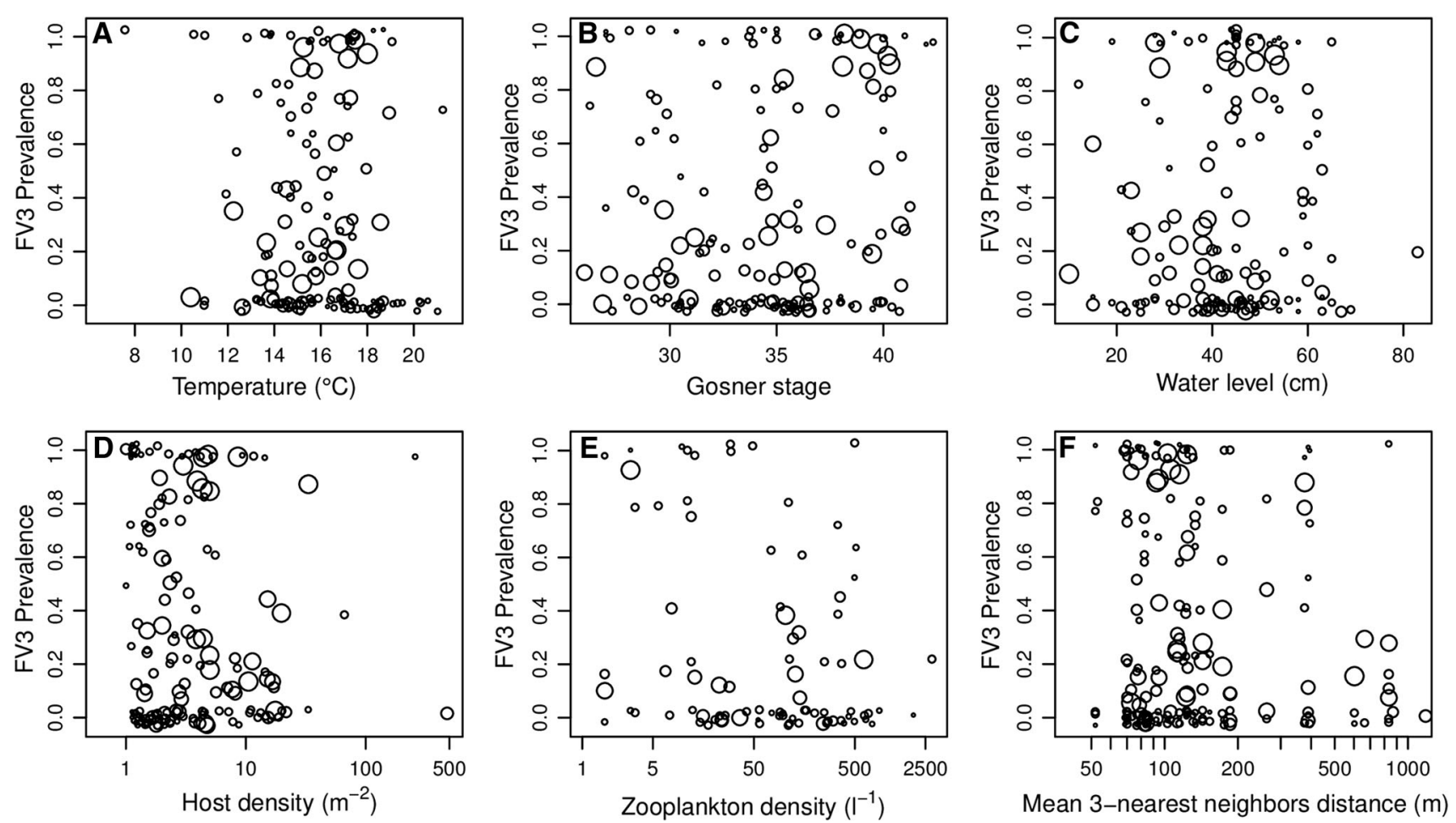

Fig. 2. Observed Frog virus 3 prevalence in relation to environmental covariates water temperature (a), developmental stage (b), pond water level (c), host density (d), zooplankton density (e), and average distance to the three nearest neighboring ponds (f) on Frog virus 3 prevalence. Prevalence values are jittered along the y-axis by up to 0.03 units to alleviate overplotting. Symbol size reflects the number of successfully assayed tadpoles in a given sample.

markedly with increasing zooplankton densities $(\beta=-$ 0.63 , 95\% CI $(-0.75,-0.51)$; Fig. 2e). Prevalence decreased slightly with increasing distance to neighboring pools $(\beta=-0.70,95 \%$ CI $(-1.04,-0.37)$; Fig. 2 f), although a model without this predictor had a similar predictive accuracy ( $\Delta \mathrm{IC}=8, \mathrm{SE} 18$; Table $\mathrm{S} 1$ ). There was also some evidence that prevalence increased slightly as frogs approached metamorphosis (i.e., Gosner stage 42; ( $\beta=0.08,95 \%$ CI $(-0.01,0.17)$; Fig. $2 b)$. Models incorporating fewer covariates exhibited a substantially lower predictive accuracy (Table S1).

\section{Discussion}

The results of this study showed that low temperature, high host density, low zooplankton concentrations, deep water, the close vicinity of other pools, and host Gosner stages approaching metamorphosis were predictors of high FV3 prevalence (Fig. 3). These results showed how responses of ranaviruses and hosts to environmental conditions tested in controlled laboratory, or even mesocosm, experiments, may not be representative of what can be expected in a natural setting. These findings also provided novel evidence that zooplankton may play a significant role in reducing prevalence of ranaviruses in the natural environment-a phenomenon previously only studied in laboratory settings (Johnson and Brunner 2014).

Individual parameters in this study did not conform to previously reported results for several possible reasons. Water temperature was included in all best fit candidates for both models and produced negative trends with respect to FV3 prevalence. This was in contrast to controlled studies supporting positive trends (Bayley et al. 2013; Brand et al. 2016). However, unlike in laboratory settings, temperature levels fluctuated with daily and seasonal cycles and were not controlled and/or stable in these wild populations. Temperature, as measured in this study, therefore likely also captures other aspects of the forest environment and interacts with other variables in the natural environment. Temperature effects are therefore not straightforward to compare between laboratory 

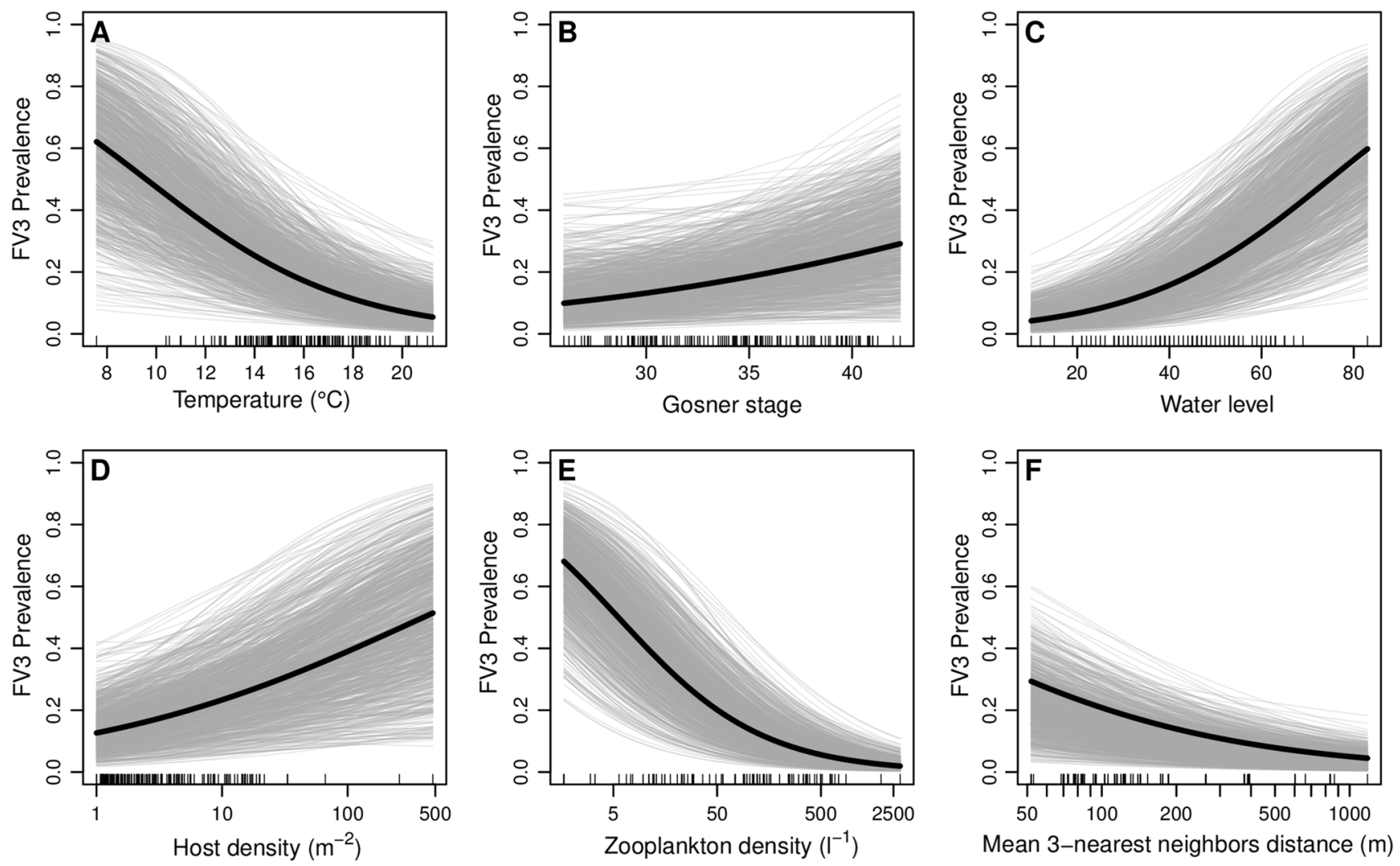

Fig. 3. Partial effects of environmental covariates water temperature (a), developmental stage (b), pond water level (c), host density (d), zooplankton density (e), and average distance to the three nearest neighboring ponds (f) on Frog virus 3 prevalence, as estimated in the best predictive model. Black lines represent posterior means of regression coefficients, gray lines are 1000 draws from the posterior of each regression coefficient. Predictor observations are indicated by the black tick marks along the $\mathrm{x}$-axes.

studies and observations of free-living populations. As previously mentioned, and as demonstrated, e.g., in the frog-chytrid fungus system (Raffel et al. 2013), effects of temperature on ranaviruses depend on both host susceptibility/immunity and pathogen replication/virulence. In this study, the detrimental effects of cold temperatures on host immunity may have overshadowed the effects of cold temperatures on FV3 virulence. Future studies at Heiberg should include surveillance of L. clamitans tadpoles in the fall, after L. sylvaticus have metamorphosed and temperatures decrease.

Although over $90 \%$ of the posterior mass for the effect of developmental stage on virus prevalence was positive, the credible interval did contain zero. This finding-a lack of a strong effect of increased prevalence with Gosner stage-is generally consistent with the existing literature, which has found a positive association between Gosner stage and ranavirus prevalence for certain ranids (Haislip et al. 2011; Warne et al. 2011), but no effect for others (Gray et al. 2007; Haislip et al. 2011)
Density was included as a predictor in best fit models. Prevalence increased with increasing density, as may be expected from increased contact rates. Density-dependent infection with ranaviruses has been suggested based on some field studies (Green et al. 2002, Brunner et al. 2004, but in other studies was either not a significant factor (Harp and Petranka 2006) or not investigated (Gray et al. 2007). Generally, "host density" from a disease transmission perspective is incredibly difficult to assess in a natural setting (and specifically this study) for several reasons. Larval amphibians other than the target species were often present in pools, and their density was not quantified. These species often occupied the same feeding niches and aquatic zones (e.g., A. maculatum mostly remained in warm littoral zones or under leaf litter-the same areas in which L. clamitans most often occurred; personal observation), thus potentially contributing to stress and greater transmission rates from increased contact. When overall pool density was low, tadpoles would often aggregate, thus increasing rates of contact. This same phenomenon was 
observed by Greer et al. (2008), in a study of density and ATV transmission among tiger salamanders (Ambystoma tigrinum). It is also virtually impossible in a natural setting to differentiate between density of infected individuals and density of susceptible hosts. Infection and mortality rates largely depend on the viral dose at which susceptible hosts are exposed (Brunner et al. 2005; Echaubard et al. 2010), and susceptible host density alone does not have significant effects on either infection or mortality (Greer et al. 2008; Echaubard et al. 2010; Reeve et al. 2013).

The best fit model also predicted an increase in prevalence with increasing water depth. This may in part be a further reflection of the negative temperature-prevalence relationship we found, as deeper pools tend to provide a larger volume of habitat at lower water temperatures, a fact that is likely not well captured by the point measurements of temperature used as predictor in the statistical model. Furthermore, deeper pools would tend to not completely freeze down to the sediment during the winter, which may support overwintering of infected green frogs.

Non-amphibian community assemblages are often overlooked in studies of ranaviruses, and microbial and microinvertebrate communities may have substantial effects on pathogen virulence. Ranaviruses survive longer in sterilized environments (Nazir et al. 2012; Johnson and Brunner 2014; Munro et al. 2016), suggesting microbial competition may be a factor in reducing replication rates and infectivity. Zooplankton, specifically Daphnia spp., has been studied as potential biological control agents for another deadly amphibian disease, chytrid, caused by the fungus Batrachochytrium dendrobatidis. Daphnia spp. ingest zoospores and significantly decrease concentrations of $B$. dendrobatidis in the environment (Buck et al. 2011). Johnson and Brunner (2014) observed a similar phenomenon with Daphnia and FV3; although Daphnia did not decrease the abundance of FV3, infectivity was reduced. The authors speculated virus particles were somehow mechanically inactivated by the digestive processes of Daphnia. In this study, Daphnia observations were too sparse to use as a predictor, but total zooplankton (which included Daphnia spp.) was a predictor that substantially improved predictive accuracy of models (Table S1). Pools with high zooplankton concentrations had substantially lower FV3 prevalence than pools with less than c. 50 individuals per liter (Fig. 2e). This finding suggests microinvertebrate communities may have been overlooked thus far in the field of amphibian ranavirus research. Although Daphnia have been previously studied in controlled laboratory experiments, other zooplankton should be included in future research; in this study, "total zooplankton" also included copepods, ostracods, and non-Daphnia cladoceran species (Holmes et al. 2016).

Clustering of pools had a small effect on FV3 prevalence, although including this parameter only provided a marginal improvement of predictive accuracy, when all other predictors were also considered. Spatial characteristics should be important drivers of transmission as sublethally infected adults travelling between sites could be sources of infection; however, we did not find this to be a strong predictor of FV3 prevalence in this system (also see Gahl and Calhoun 2008; Greer et al. 2009). Other potentially predictive parameters in future studies may be pool geographic locations, as pools at lower elevations and therefore lower catchment areas could receive more inputs from runoff (Gahl and Calhoun 2008).

Surveillance methods were not adequate to make inferences about FV3 transmission dynamics in this system, given the relatively sparse sampling in time, and because logistical constraints prohibited us from sampling all potential sites harboring outbreaks. Surveillance for FV3 detection in this study included the two most commonly observed anuran species, but in future studies involving transmission, other amphibian taxa must be considered. Several other larvae of aquatic-breeding amphibians were observed in the study pools, including (in order of decreasing abundance) spring peepers (Pseudacris crucifer), spotted salamanders (Ambystoma maculatum), American toads (Anaxyrus americanus), Eastern red-spotted newts (Notophthalmus viridescens), and American bullfrogs (Lithobates catesbeianus). Each of these species is susceptible, to some degree, to ranaviruses (Green et al. 2002; Gahl and Calhoun 2010; Hoverman et al. 2011, 2012; Richter et al. 2013) and could be additional sources of infection for L. sylvaticus and L. clamitans. Sub-clinically infected adults of these species also serve as potential reservoirs and may introduce ranaviruses to other populations, or re-introduce the virus in subsequent years (Brunner et al. 2004; North et al. 2015).

Pool geomorphology is also an important consideration especially with constructed ponds. Higher prevalence of ranaviruses has been associated with constructed vs natural wetlands, which has been attributed to deeper basin shapes with little to no littoral zones, longer hydroperiods and less emergent vegetation (Petranka et al. 2003; Greer and Collins 2008; Richter et al. 2013), and utilization of ponds for cattle (Gray et al. 2007). Although study ponds at 
Heiberg were constructed, they were not representative of the "constructed ponds" referenced in the literature as having higher prevalence for several reasons. The Heiberg pools were located within a mainly densely forested landscape with no agricultural use or livestock access. Most pool basins were gradually sloping, creating the broader littoral zones characteristic of natural pools. Although we did not quantify aquatic vegetation, we observed abundant vegetation (submergent, emergent, and free-floating) in many constructed ponds during sampling. Vegetation is a recommended parameter to include in future studies, as tadpoles may be more spatially distributed in ponds with greater vegetation thus decreasing rates of contact (Greer and Collins 2008). In these regards, constructed ponds at Heiberg appeared to mimic natural systems, with the exception of hydroperiod. Most ponds remained permanently filled, and the few that did not either contained no amphibian larvae or dried before larvae could reach metamorphosis (Fig. 1).

Ranaviruses cause mortality and may lead to reduced fitness, but aquatic-breeding amphibians in particular are already subject to an onslaught of challenges prior to metamorphosis, with field mortality rates for larval anurans exceeding an average of 90\% (Melvin and Houlahan 2012). This makes it difficult to determine the degree to which ranavirus-caused mortality exceeds the background rate. Continued disease surveillance therefore needs to be coupled with longitudinal population monitoring to detect long-term population effects of ranavirus prevalence; however, our study has provided additional insights into ways of immediately reducing ranavirus infection and mortality in newly constructed ponds closely mimicking natural systems. Many factors must be taken into consideration when designing constructed wetlands such as-to name just a few-proximity to anthropogenic influence, hydrological catchment, availability of amphibian source populations, predation risk, e.g., accessibility of the wetland to fish. In addition, by designing ponds with locations and basin geomorphologies favoring warmer temperatures, and stocking to establish a plankton community, we may further reduce disease risk and promote thriving populations in artificial wetlands.

\section{ACKNOWLEDGEMENTS}

We thank the Maurice Alexander memorial research fund, Western New York Herpetological Society, and SUNY ESF
Graduate Student Association for funding. We also thank the Upper Susquehanna Coalition and SUNY ESF for access to forest properties, JB for molecular protocols, RO at Cornell University Animal Health Diagnostic Center, and JA, LO, LL, CR, GG and RS for field and laboratory assistance. Collection methods for live amphibians followed approved SUNY ESF IACUC protocol \#140201.

\section{OPEN Access}

This article is distributed under the terms of the Creative Commons Attribution 4.0 International License (http://c reativecommons.org/licenses/by/4.0/), which permits unrestricted use, distribution, and reproduction in any medium, provided you give appropriate credit to the original author(s) and the source, provide a link to the Creative Commons license, and indicate if changes were made.

\section{REFERENCES}

Ariel E, Nicolajsen N, Christophersen M-B, Holopainen R, Tapiovaara H, Bang Jensen B (2009) Propagation and isolation of ranaviruses in cell culture. Aquaculture 294:159-164

Bayley A, Hill B, Feist S (2013) Susceptibility of the European common frog Rana temporaria to a panel of ranavirus isolates from fish and amphibian hosts. Diseases of Aquatic Organisms 103:171-183

Brand MD, Hill RD, Brenes R, Chaney JC, Wilkes RP, Grayfer L, Miller DL, Gray MJ (2016) Water temperature affects susceptibility to ranavirus. EcoHealth 13:350-359

Brunner JL, Richards K, Collins JP (2005) Dose and host characteristics influence virulence of ranavirus infections. Oecologia 144:399-406

Brunner JL, Schock DM, Davidson EW, Collins JP (2004) Intraspecific reservoirs: complex life history and the persistence of a lethal ranavirus. Ecology 85:560-566

Buck JC, Truong L, Blaustein AR (2011) Predation by zooplankton on Batrachochytrium dendrobatidis: biological control of the deadly amphibian chytrid fungus? Biodiversity and Conservation 20:3549-3553

Carpenter B, Gelman A, Hoffman MD, Lee D, Goodrich B, Betancourt M, Brubaker M, Guo J, Li P, Riddell A (2017) Stan: a probabilistic programming language. Journal of Statistical Software $76: 1-32$

Clark K, Karsch-Mizrachi I, Lipman DJ, Ostell J, Sayers EW (2016) GenBank. Nucleic Acids Research 44(D1):D67-72

Duffus ALJ, Waltzek TB, Stohr AC, Allender MC, Gotesman M, Whittington RJ, Hick P, Hines MK, Marschang RE. 2015. Distribution and Host Range of Ranaviruses. In: Ranaviruses: Lethal Pathogens of Ectothermic Vertebrates. Springer International Publishing, pp 9-57. 
Echaubard P, Leduc J, Pauli B, Chinchar VG, Robert J, Lesbarrères D (2014) Environmental dependency of amphibian-ranavirus genotypic interactions: evolutionary perspectives on infectious diseases. Evolutionary Applications 7:723-733

Echaubard P, Little K, Pauli B, Lesbarrères D (2010) Contextdependent effects of ranaviral infection on Northern leopard frog life history traits. PloS ONE 5:e13723

Forson DD, Storfer A (2006) Atrazine increases ranavirus susceptibility in the tiger salamander, Ambystoma tigrinum. Ecological Applications 16:2325-2332

Gahl M, Calhoun A (2008) Landscape setting and risk of Ranavirus mortality events. Biological Conservation 141:2679-2689

Gahl MK, Calhoun AJK (2010) The role of multiple stressors in ranavirus-caused amphibian mortalities in Acadia National Park wetlands. Canadian Journal of Zoology 88:108-121

Gelman A, Jakulin A, Pittau MG, Su Y-S (2008) A weakly informative default prior distribution for logistic and other regression models. Annals of Applied Statistics 2:1360-1383

Gosner KL (1960) A simplified table for staging anuran embryos and larvae with notes on identification. Herpetologica 16:183-190

Gray MJ, Miller DL, Schmutzer AC, Baldwin CA (2007) Frog virus 3 prevalence in tadpole populations inhabiting cattle-access and non-access wetlands in Tennessee, USA. Diseases of Aquatic Organisms 77:97-103

Green D, Converse KA, Schrader AK (2002) Epizootiology of sixty-four amphibian morbidity and mortality events in the USA, 1996-2001. Annals of the New York Academy of Sciences 969:323-339

Greer AL, Briggs CJ, Collins JP (2008) Testing a key assumption of host-pathogen theory: density and disease transmission. Oikos 117:1667-1673

Greer AL, Brunner JL, Collins JP (2009) Spatial and temporal patterns of Ambystoma tigrinum virus (ATV) prevalence in tiger salamanders Ambystoma tigrinum nebulosum. Diseases of Aquatic Organisms 85:1-6

Greer AL, Collins JP (2008) Habitat fragmentation as a result of biotic and abiotic factors controls pathogen transmission throughout a host population. Journal of Animal Ecology 77:364-369

Haislip NA, Gray MJ, Hoverman JT, Miller DL (2011) Development and disease: How susceptibility to an emerging pathogen changes through anuran development. PLoS ONE 6:e22307

Harp EM, Petranka JW (2006) Ranavirus in wood frogs (Rana sylvatica): potential sources of transmission within and between ponds. Journal of Wildlife Diseases 42:307-318

Holmes CJ, Figary S, Schulz KL, Cáceres CE (2016) Effects of diversity on community assembly in newly formed pond communities. Ecosphere 7:e01377

Hoverman JT, Gray MJ, Haislip NA, Miller DL (2011) Phylogeny, life history, and ecology contribute to differences in amphibian susceptibility to ranaviruses. EcoHealth 8:301-319

Hoverman JT, Gray MJ, Miller DL, Haislip NA (2012) Widespread occurrence of ranavirus in pond-breeding amphibian populations. EcoHealth 9:36-48

Jancovich JK, Davidson EW, Parameswaran N, Mao J, Chinchar VG, Collins JP, Jacobs BL, Storfer A (2005) Evidence for emergence of an amphibian iridoviral disease because of human-enhanced spread. Molecular Ecology 14:213-224

Johnson A, Brunner J (2014) Persistence of an amphibian ranavirus in aquatic communities. Diseases of Aquatic Organisms 111:129-138
Johnson M, Zaretskaya I, Raytselis Y, Merezhuk Y, McGinnis S, Madden TL (2008) NCBI BLAST: a better web interface. Nucleic Acids Research 36:W5-W9

Mao J, Hedrick R, Chinchar V (1997) Molecular characterization, sequence analysis, and taxonomic position of newly isolated fish iridoviruses. Virology 229:212-220

McElreath R. 2016. Statistical Rethinking-A Bayesian Course with Examples in $\mathrm{R}$ and Stan. CRC Press

Melvin SD, Houlahan JE (2012) Tadpole mortality varies across experimental venues: do laboratory populations predict responses in nature? Oecologia 169:861-868

Miller DL, Gray MJ, Rajeev S, Schmutzer AC, Burton EC, Merrill A, Baldwin CA (2009) Pathologic findings in larval and juvenile anurans inhabiting farm ponds in Tennessee, USA. Journal of Wildlife Diseases 45:314-324

Munro J, Bayley AE, McPherson NJ, Feist SW (2016) Survival of Frog virus 3 in Freshwater and Sediment from an English Lake. Journal of Wildlife Diseases 52:138-142

Nazir J, Spengler M, Marschang RE (2012) Environmental persistence of amphibian and reptilian ranaviruses. Diseases of Aquatic Organisms 98:177-184

North AC, Hodgson DJ, Price SJ, Griffiths AGF. 2015. Anthropogenic and Ecological Drivers of Amphibian Disease (Ranavirosis). Kerby JL, editor. PLoS ONE 10:e0127037.

Pallister J, Gould A, Harrison D, Hyatt A, Jancovich J, Heine H (2007) Development of real-time PCR assays for the detection and differentiation of Australian and European ranaviruses. Journal of Fish Diseases 30:427-438

Paull SH, Johnson, PTJ 2018. How temperature, pond-drying, and nutrients influence parasite infection and pathology. EcoHealth.

Petranka JW, Murray SS, Kennedy CA (2003) Responses of amphibians to restoration of a southern Appalachian wetland: perturbations confound post-restoration assessment. Wetlands 23:278-290

Raffel TR, Romansic JM, Halstead NT, McMahon TA, Venesky MD, Rohr JR (2013) Disease and thermal acclimation in a more variable and unpredictable climate. Nature Climate Change 3:146-151

Reeve BC, Crespi EJ, Whipps CM, Brunner JL (2013) Natural Stressors and Ranavirus Susceptibility in Larval Wood Frogs (Rana sylvatica). EcoHealth 10:1-11

Richter SC, Drayer AN, Strong JR, Kross CS, Miller DL, Gray MJ (2013) High prevalence of ranavirus infection in permanent constructed wetlands in Eastern Kentucky, USA. Herpetol. Rev. 44:464-466

Rojas S, Richards K, Jancovich JK, Davidson EW (2005) Influence of temperature on Ranavirus infection in larval salamanders Ambystoma tigrinum. Diseases of Aquatic Organisms 63:95-100

Sambrook J, Russell DW. 2001. Molecular cloning: a laboratory manual. Cold Spring Harb. Lab. Press Cold Spring Harb. N. Y. 2

Storfer A, Alfaro ME, Ridenhour BJ, Jancovich JK, Mech SG, Parris MJ, Collins JP (2007) Phylogenetic concordance analysis shows an emerging pathogen is novel and endemic. Ecology Letters 10:1075-1083

Vehtari A, Gelman A, Gabry J (2017) Practical Bayesian model evaluation using leave-one-out cross-validation and WAIC. Statistics and Computing 27:1413-1432

Warne RW, Crespi EJ, Brunner JL (2011) Escape from the pond: stress and developmental responses to ranavirus infection in wood frog tadpoles. Functional Ecology 25:139-146 
Watanabe S (2010) Asymptotic equivalence of Bayes cross validation and widely applicable information criterion in singular learning theory. Journal of Machine Learning Research 11:35713594

Werner EE, Skelly DK, Relyea RA, Yurewicz KL (2007) Amphibian species richness across environmental gradients. Oikos 116:1697-1712
Youker-Smith TE, Whipps CM, Ryan SJ (2016) Detection of an FV3-like Ranavirus in Wood Frogs (Lithobates sylvaticus) and Green Frogs (Lithobates clamitans) in a Constructed Vernal Pool Network in Central New York State. Herpetological Reviews 47:595-598 